\title{
A rare case of polyostotic fibrous dysplasia detected on ${ }^{18} \mathrm{~F}$-rhPSMA-7 $\mathrm{PET} / \mathrm{CT}$
}

\author{
Hui Wang ${ }^{1} \cdot$ Matthias Eiber $^{1} \cdot$ Thomas Langbein $^{1}$ \\ Received: 30 December 2019 / Accepted: 3 March 2020 / Published online: 16 April 2020 \\ (C) The Author(s) 2020
}

The prostate-specific membrane antigen (PSMA) has been proven to show high expression in prostate cancer cells [1]. The high binding affinity and internalization of PSMA radioligands makes it an excellent molecular target for theranostics of prostate cancer [1]. Positron emission tomography/computed tomography (PET/CT) using novel PSMA-targeting probes is increasingly used in recurrent and metastastic prostate cancer [2]. In addition, it is increasingly being used as an imaging modality for initial staging [3]. ${ }^{18} \mathrm{~F}$ rhPSMA-7 is a new theranostic PSMA-targeting agent which allows radiolabeling with ${ }^{18} \mathrm{~F}$ and radiometals and is associated with minimal renal excretion [4]. However, physiologic and other pathologic forms of tracer uptake have to be considered carefully as potential pitfalls to image interpretation, such as ganglia, healing fracture, adrenal adenoma, primary lung cancer, and metastatic renal cell carcinoma [5].

Fibrous dysplasia is an uncommon skeletal disorder, accounting for 5 to $7 \%$ of all benign bone tumors [6]. Around $75 \%$ of cases have a monostotic form with only one bone involved, commonly the craniofacial bones, but the ribs, femur, and tibia may also be involved [7, 8]. PSMA-ligand uptake has been reported in monostotic (rib) fibrous dysplasia using ${ }^{68} \mathrm{Ga}$-PSMA-PET/CT, and this has to be differentiated from prostate cancer bone metastases [9]. Here, we present a case of uncommon polyostotic fibrous dysplasia identified on PSMA PET/CT imaging.

An 80-year-old man with histologically confirmed prostate cancer (Gleason score 7a, iPSA $4.26 \mathrm{ng} / \mathrm{mL}$ ) by transurethral resection of the prostate (TUR-P) performed in February 2018 underwent ${ }^{18} \mathrm{~F}$-rhPSMA-7 PET/CT imaging for staging in October 2018. No focal uptake in the prostate bed and no evidence of pelvic lymph node metastases was seen. However, intense tracer uptake was observed in the right parietal skull, in the left 3rd, 8th, and 9th ribs, and in the left ilium (red arrows in $a \mathrm{MIP}$ and $d+e \mathrm{PET}$ ). The corresponding bone scan performed 2 weeks earlier had shown hypermetabolic lesions in the same areas ( $b$ bone scan). Finally, typical CT morphologic findings, including expansive changes with ground-glass appearance, cortical erosion, diffuse sclerosis, and well-circumscribed margins could be observed and, therefore, clearly confirmed radiologically polyostotic fibrous dysplasia $(c \mathrm{CT})$ [10].

This case indicates that a thorough review of the $\mathrm{CT}$ dataset of a hybrid PSMA-ligand PET/CT is not only useful to correctly identify solitary or isolated lesions but also mandatory to avoid a potential pitfall and correctly differentiate extensive polyostotic fibrous dysplasia from metastatic bone lesions [11] when PSMA-ligand uptake in the bone is seen.

This article is part of the Topical Collection on Image of the month

Matthias Eiber

matthias.eiber@tum.de

1 Department of Nuclear Medicine, Klinikum rechts der Isar, Technical University of Munich, School of Medicine, Ismaninger Straße 22, 81675 Munich, Germany 


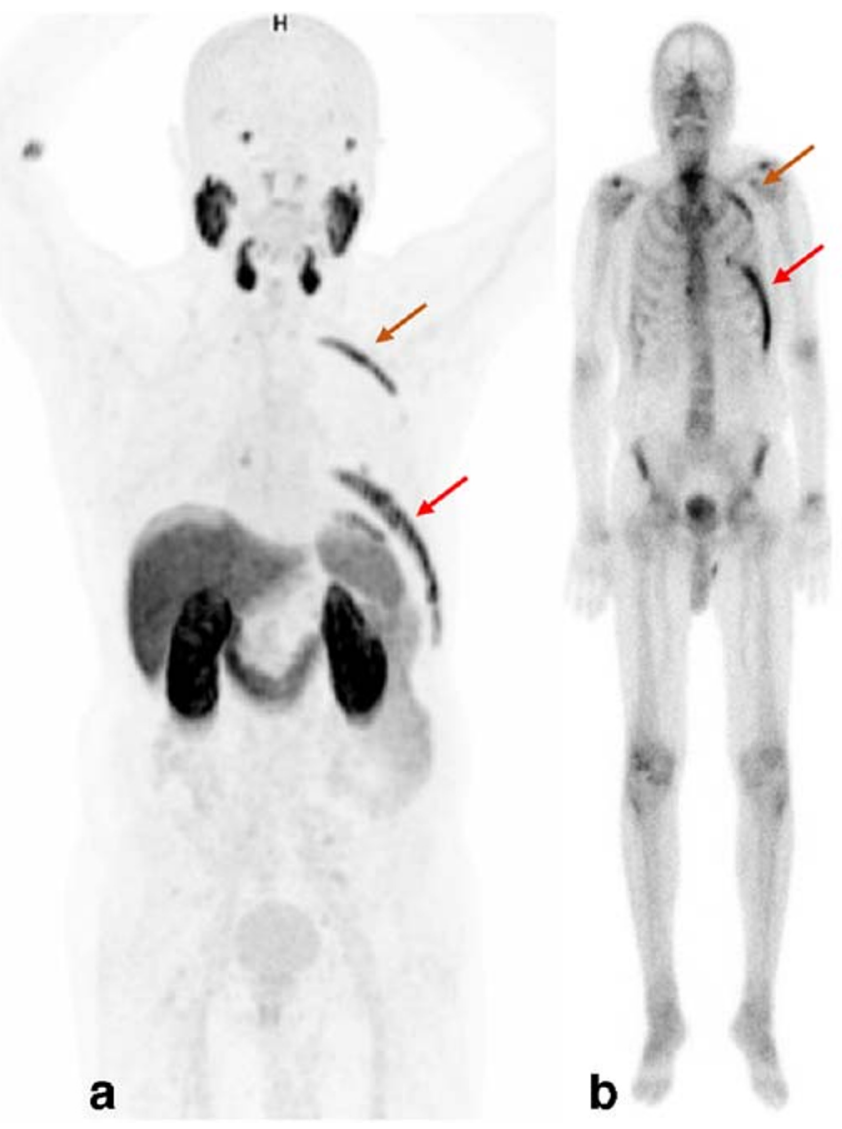

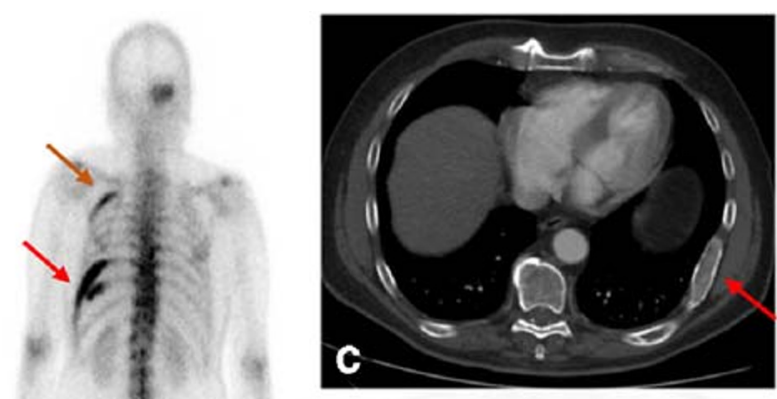
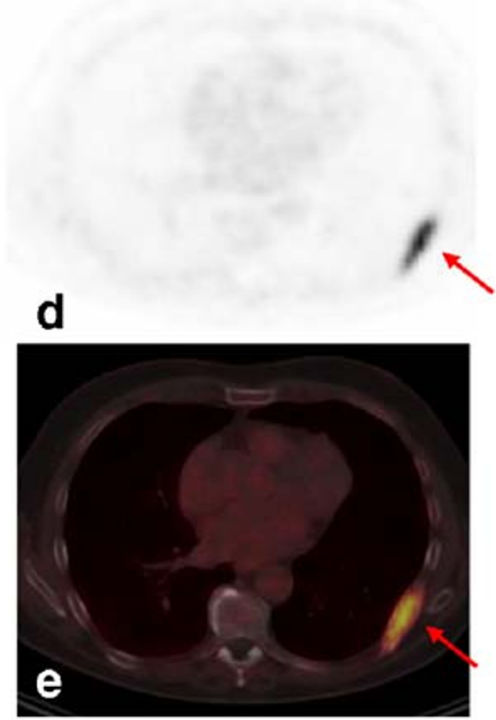

Authors' contributions All authors contributed to the study conception and design. All authors read and approved the final manuscript.

Funding information Open Access funding provided by Projekt DEAL. Matthias Eiber received funding from the SFB 824 (DFG Sonderforschungsbereich 824 , project B11) from the Deutsche Forschungsgemeinschaft, Bonn, Germany, and from Blue Earth Diagnostics (licensee for rhPSMA) as part of an academic collaboration.

\section{Compliance with ethical standards}

Conflict of interest Matthias Eiber is named as an inventor on a patent application for rhPSMA. Matthias Eiber is a consultant for Blue Earth Diagnostics. No other potential conflict of interest relevant to this article was reported.

Ethics approval All procedures performed in studies involving patients were in accordance with the ethical standards of the institutional research committee and with the Helsinki declaration.

Consent to participate During our research, informed consent for each patient was obtained as patient privacy rights and they were always observed. Written informed consent was obtained from the patient.

Consent for publication Written informed consent for publication of their clinical details and/or clinical images was obtained from the patient.
Open Access This article is licensed under a Creative Commons Attribution 4.0 International License, which permits use, sharing, adaptation, distribution and reproduction in any medium or format, as long as you give appropriate credit to the original author(s) and the source, provide a link to the Creative Commons licence, and indicate if changes were made. The images or other third party material in this article are included in the article's Creative Commons licence, unless indicated otherwise in a credit line to the material. If material is not included in the article's Creative Commons licence and your intended use is not permitted by statutory regulation or exceeds the permitted use, you will need to obtain permission directly from the copyright holder. To view a copy of this licence, visit http://creativecommons.org/licenses/by/4.0/.

\section{References}

1. Farolfi A, Fendler W, Iravani A, Haberkorn U, Hicks R, Herrmann $\mathrm{K}$, et al. Theranostics for advanced prostate cancer: current indications and future developments. Eur Urol Oncol. 2019;2(2):152-62. https://doi.org/10.1016/j.euo.2019.01.001.

2. Calais J, Ceci F, Eiber M, Hope TA, Hofman MS, Rischpler C, et al. (18)F-fluciclovine PET-CT and (68)Ga-PSMA-11 PET-CT in patients with early biochemical recurrence after prostatectomy: a prospective, single-centre, single-arm, comparative imaging trial. Lancet Oncol. 2019;20(9):1286-94. https://doi.org/10.1016/ s1470-2045(19)30415-2. 
3. Mottet N, van den Bergh RCN, Briers E, Cornford P, De Santis M, Fanti S, Gillessen S, Grummet J, Henry AM, Lam TB, Mason MD, van der Kwast TH, van der Poel HG, Rouvière O, Tilki D, Wiegel T. EAU Guidelines. 2019. https://uroweb.org/guidelines/2019. Accessed 2 Dec 2019

4. Oh SW, Wurzer A, Teoh EJ, Oh S, Langbein T, Kronke M, et al. Quantitative and qualitative analyses of biodistribution and PET image quality of novel radiohybrid PSMA, (18)F- rhPSMA-7, in patients with prostate cancer. J Nucl Med. 2019. https://doi.org/10. 2967/jnumed.119.234609.

5. Sheikhbahaei S, Afshar-Oromieh A, Eiber M, Solnes LB, Javadi MS, Ross AE, et al. Pearls and pitfalls in clinical interpretation of prostate-specific membrane antigen (PSMA)-targeted PET imaging. Eur J Nucl Med Mol Imaging. 2017;44(12):2117-36. https:// doi.org/10.1007/s00259-017-3780-7.

6. Hakim DN, Pelly T, Kulendran M, Caris JA. Benign tumours of the bone: a review. J Bone Oncol. 2015;4(2):37-41.

7. Feller L, Wood NH, Khammissa RA, Lemmer J, Raubenheimer EJ. The nature of fibrous dysplasia. Head Face Med. 2009;5(1):1-5.
8. Riddle ND, Bui MM. Fibrous dysplasia. Arch Pathol Lab Med. 2013;137(1):134-8. https://doi.org/10.5858/arpa.2012.0013-RS.

9. Plouznikoff N, Garcia C, Artigas C, Entezari K, Flamen P. Heterogeneity of 68Ga-PSMA PET/CT uptake in fibrous dysplasia. Clin Nucl Med. 2019;44(10):e593-e4. https://doi.org/10.1097/rlu. 0000000000002609 .

10. Fitzpatrick KA, Taljanovic MS, Speer DP, Graham AR, Jacobson JA, Barnes GR, et al. Imaging findings of fibrous dysplasia with histopathologic and intraoperative correlation. AJR Am J Roentgenol. 2004;182(6):1389-98. https://doi.org/10.2214/ajr. 182.6.1821389.

11. De Coster L, Sciot R, Everaerts W, Gheysens O, Verscuren R, Deroose CM, et al. Fibrous dysplasia mimicking bone metastasis on (68)GA-PSMA PET/MRI. Eur J Nucl Med Mol Imaging. 2017;44(9):1607-8. https://doi.org/10.1007/s00259-017-3712-6.

Publisher's note Springer Nature remains neutral with regard to jurisdictional claims in published maps and institutional affiliations. 